\title{
Identification of the calcitonin receptor in osteoarthritic chondrocytes
}

\author{
Toni Segovia-Silvestre ${ }^{1}$, Caroline Bonnefond ${ }^{1}$, Bodil C Sondergaard ${ }^{1}$, Tjorbjoern Christensen ${ }^{2}$, Morten A Karsdal ${ }^{1}$ \\ and Anne C Bay-Jensen ${ }^{1 *}$
}

\begin{abstract}
Background: Preclinical and clinical studies have shown that salmon calcitonin has cartilage protective effects in joint degenerative diseases, such as osteoarthritis (OA). However, the presence of the calcitonin receptor (CTR) in articular cartilage chondrocytes is yet to be identified. In this study, we sought to further investigate the expression of the CTR in naïve human OA articular chondrocytes to gain further confirmation of the existents of the CTR in articular cartilage.

Methods: Total RNA was purified from primary chondrocytes from articular cartilage biopsies from four OA patients undergoing total knee replacement. High quality CDNA was produced using a dedicated reverse transcription polymerase chain reaction (RT-PCR) protocol. From this a nested PCR assay amplifying the full coding region of the CTR mRNA was completed. Western blotting and immunohistochemistry were used to characterize CTR protein on protein level in chondrocytes.

Results: The full coding transcript of the CTR isoform 2 was identified in all four individuals. DNA sequencing revealed a number of allelic variants of the gene including two potentially novel polymorphisms: a frame shift mutation, $+473 \mathrm{del}$, producing a shorter form of the receptor protein, and a single nucleotide polymorphism in the 3' non coding region of the transcript, +1443 C>T. A 53 kDa protein band, consistent with non-glycosylated CTR isoform 2, was detected in chondrocytes with a similar size to that expressed in osteoclasts. Moreover the CTR was identified in the plasma membrane and the chondrocyte lacuna of both primary chondrocytes and OA cartilage section.
\end{abstract}

Conclusions: Human OA articular cartilage chondrocytes do indeed express the CTR, which makes the articular a pharmacological target of salmon calcitonin. In addition, the results support previous findings suggesting that calcitonin has a direct anabolic effect on articular cartilage.

\section{Background}

In vitro studies have shown that salmon calcitonin ( $\mathrm{sCT}$ ) attenuates proteolysis in articular cartilage, inhibiting collagenase and phospholipase A2 activities [1,2]. Simultaneous induction of the intracellular second messenger cyclic adenosine 3'5'-monophosphate (cAMP) and down-regulation of MMP has been observed in bovine articular cartilage explants in response to sCT [3]. Moreover, sCT has been reported to induce anabolic effects on cartilage formation, proteoglycan and glycosaminoglycan syntheses in chondrocytes and growth plate

\footnotetext{
* Correspondence: acbj@nordicbioscience.com

'Nordic Bioscience A/S, Herlev Hovedgade 207, 2730 Herlev, Denmark

Full list of author information is available at the end of the article
}

cultures from different species [4-7]. In vivo, long-term $\mathrm{sCT}$ treatment has been shown to increase the number of hypertrophic chondrocytes and thickness of the epiphyseal plate in young rats [8]. In addition, a number of studies have documented the palliative effects of CT in different joint damage animal models [9-12]. Finally, the effect of $\mathrm{SCT}$ on cartilage degradation and pain alleviation was recently demonstrated in different clinical settings where osteoarthritis $(\mathrm{OA})$ patients were treated with salmon calcitonin $[13,14]$. Thus there are several indications that modulation of the calcitonin receptor (CTR) is a valid target for treatment of joint degenerative diseases. However, the mode of action of which sCT exerts its effect on cartilage need to be further investigated.

\section{() Biomed Central}


The physiological effects of sCT in humans are mediated through high-affinity CT receptors (CTR) - a class B of the G-protein coupled receptor (GPCR) family. The binding of $\mathrm{sCT}$ to its receptor produces intracellular accumulation of cAMP [15]. The CTR has been cloned and partially characterized in different cell types and species [16-18], and a number of CTR isoforms have been identified so far. In humans, CTR isoforms are known to arise from alternative splicing of the primary transcript $[19,20]$ of a unique gene (CALCR) located at chromosome 7q21.3 [21]. The two most common human variants differ in a 16-amino acid insert in the putative first intracellular loop [22,23] and this feature confers them different abilities to activate the cAMP and protein kinase $C$ (PKC) signal transduction pathways $[24,25]$. A different splice variant lacking both the 16-amino acid insert in the first intracellular domain as well as the first 47 amino acids of the amino-terminus extracellular domain was reported to bind to $\left[{ }^{125} \mathrm{I}\right]$ sCT with high affinity and responding to human CT with increases in cAMP [26]. The significance of two most recently discovered isoforms [27] is still unknown. A further human CTR variant results from a T-to-C base mutation producing a leucine 447 to proline (L447P) amino acid change. This substitution has no apparent effect on ligand binding or receptor function in vitro [28], but has been associated with decreased fracture risk in postmenopausal women in different studies $[29,30]$. In summary, CTR variants appear to present different binding properties and ability to couple to signal transduction pathways. Currently, the occurrence, expression regulation and physiological significance of those variants are largely unknown.

The effects of sCT on bone have been demonstrated to be mediated by direct binding of the hormone to CTRs expressed by osteoclasts in their basolateral membrane [31]. In contrast, no conclusive evidence of the expression of the CTR in cartilage has been provided yet. Our group has previously reported the existence of an intron spanning sequence of the coding region of CALCR mRNA in bovine articular cartilage [32]. In contrast, Lin and colleagues concluded that the CTR is not expressed in human cartilage after investigating its existence in chondrocytes cultures by polymerase chain reaction (PCR), western blotting and immunochemical analysis [33]. This controversy has left an important question unanswered: does the effect of sCT on articular cartilage occur via a direct interaction with cartilage cells or through an indirect route via inhibition of resorptive activity of osteoclasts in subchondral bone?

In the present study we attempted to test the hypothesis that the CTR is expressed in human articular cartilage. We used a specific RT-PCR DNA sequencing strategy to retrieve and identify the CTR transcript expressed in chondrocytes. We then sought to assess the expression and identity of a CTR protein consistent with the identified transcripts by western blotting and to determine its subcellular localization by immunochemical analysis.

\section{Methods}

\section{Patients' characteristics}

This investigation originally included $21 \mathrm{OA}$ patients $(17$ females and 4 males) with an average age of $66 \pm 11$ years undergoing elective total knee joint replacement surgery at the Orthopedic Surgery Unit of Gentofte hospital (Denmark). Given the characteristics of the study samples and the molecular methods performed, individual samples could not be used for simultaneous genetic and protein analysis. Therefore, results presented in this paper correspond to four patients of the study group in which complete DNA sequencing could be optimally performed. Four other patients were used for western blotting analysis, and two different patients for immunochemical analysis. The study was approved by the Ethics Committee of the Capital Region of Denmark, DK-3400 (approval no. HD-2007-0084). Patients were informed about the purpose of the study and gave written consent.

\section{Chondrocytes isolation from fresh human cartilage tissue}

Articular cartilage from non-eroded areas with a normal smooth surface and hard texture was isolated and used for experiments. Dissected specimens free of bone tissue were collected in DMEM (Lonza, Basel, Switzerland) and preserved at $4^{\circ} \mathrm{C}$ until shipment to the laboratory within 24 hours following surgery, then washed in Dulbecco's PBS buffer (Lonza) and used immediately for chondrocyte cells isolation. Cartilage was cut in $1 \mathrm{~mm}^{2}$ pieces and sequentially digested with $0.5 \%$ pronase (Sigma-Aldrich, Dorset, UK) for one hour and 0.5\% collagenase type 2 (Wako, Osaka, Japan) overnight at $37^{\circ} \mathrm{C}$. The presence of viable chondrocytes was assessed by microscopic observation. Cell pellets were directly used for RNA isolation, western blotting or immunocytochemical analysis or, alternatively, snap frozen in liquid nitrogen and stored at $-70^{\circ} \mathrm{C}$ for later use.

\section{RNA extraction from isolated chondrocytes}

After careful optimization of the RNA extraction from cartilage procedure, then RNA was isolated from four different patients. Cell lysis and RNA extraction were performed using the High-Pure RNA Isolation kit and reagents (Roche, Basel, Switzerland) following manufacturer's instructions. Six to $25 \mu \mathrm{g}$ of high quality RNA was obtained from an average of 6 million cells, resuspended in $200 \mu \mathrm{L}$ of PBS and lysed in $400 \mu \mathrm{L}$ of lysis/ binding buffer during $20 \mathrm{~min}$ of incubation on ice and 
frequent vortexing. RNA was eluted in $50 \mu \mathrm{L}$ of EB buffer (10 mM Tris-Cl, pH 8.5). RNA integrity, quality and quantity were assessed using an Agilent 2100 Bioanalyzer (Agilent Technologies, Santa Clara, CA, USA).

\section{Reverse transcription polymerase chain reaction}

Complementary DNA (cDNA) copies of chondrocyte RNA were prepared using the Transcriptor First Strand cDNA Synthesis kit (Roche). One microgram samples of high quality RNA (RNA Integrity Number (RIN) $>8$, concentration $>50 \mathrm{ng} / \mu \mathrm{L}$, no strong secondary peaks in the electropherogram, A260/280 > 1.8) were used as template in single cDNA synthesis reactions. Combined random hexamer plus anchored-oligo $(\mathrm{dT})_{18}$ primers were used in a pre-reaction mix containing RNA template and primers were first heat denatured for $10 \mathrm{~min}$ at $65^{\circ} \mathrm{C}$. Subsequently, a preincubation step at $25^{\circ} \mathrm{C}$ for 10 minutes was introduced before the reverse transcription reaction was performed at $50^{\circ} \mathrm{C}$ for 1 hour. RTPCR negative controls were carried out in parallel by substituting reverse transcriptase with water.

\section{CTR polymerase chain reaction assay}

The NCBI Reference Sequence NM_001742.2 was used as template for CALCR PCR assays design. A nested PCR strategy was adopted to amplify the entire coding region of the CTR with specificity and high reaction yields. Briefly, primers (Eurofins MWG Operon, Ebersberg, Germany) for the primary amplification from $2 \mu \mathrm{L}$ of cDNA preparation were CALCR_F (5'-CCAGTGACAGAATTCCAGGAC, sense) and CALCR_R (5'-GTCTCCCAAAGCAACAGTACC, antisense). Nested primers CALCR_NF (5'-CCAGGACAAAGAGATCTTCA, sense) and CALCR_NR (5'-CAGGAAATGATGGCTCAGTG, antisense) were used to amplify an internal target from $2 \mu \mathrm{L}$ of the primary amplification product. Herculase II Fusion DNA polymerase (Stratagene, La Jolla, CA, USA) was used in those long range PCR experiments. PCR amplifications were performed in a DYAD dual block PCR machine (MJ Research, Waltham, MA, USA) and consisted of 35 cycles of: 2 minutes denaturation at $95^{\circ} \mathrm{C} ; 20$ seconds annealing at $54^{\circ} \mathrm{C}$ for CALCR_NF/CALCR_NR and at $53^{\circ} \mathrm{C}$ for CALCR_F/CALCR_R; 49 seconds extension at $72^{\circ} \mathrm{C}$ for CALCR_NF/CALCR_NR and at 50 seconds for CALCR_F/CALCR_R. Negative controls were matched to all samples amplified. Negative control reactions to detect genomic and pseudogene DNA amplification were performed by omitting reverse transcriptase in RT-PCR reactions. Negative controls for laboratory contamination were performed using water as template in PCR reactions.

\section{DNA sequencing of nested PCR products}

DNA sequencing was performed in samples of patient cDNA amplified by nested PCR. The 1500 bp amplicon generated by the CALCR_NF/CALCR_NR assay was purified from the PCR reaction using the QIAquick PCR purification Kit (Qiagen, Hilden, Germany). Approximately 30-60 ng of purified products were sequenced using Bigdye Terminator chemistry in ABI 3730XL capillary sequencers (Applied Biosystems, Foster City, CA, USA) at Eurofins MWG Operon. Overlapping sequencing primers were designed in the 147-1647 nucleotide region of NM_001742.2 using Eurofins MWG Operon online tool. Primers covered both DNA strands of the nested PCR product aiming at excluding polymerase-mediated DNA sequence changes during PCR. For those samples showing polymorphisms or mutations a second confirmatory DNA sequencing experiment was performed starting from stored cDNA material of the patient.

\section{Western blotting analysis}

Chondrocyte pellets of about 6 million of cells were homogenized in $50 \mu \mathrm{L}$ of RIPA buffer $(140 \mathrm{mM} \mathrm{NaCl}$, $10 \mathrm{mM}$ Tris, $\mathrm{pH} 8,1 \mathrm{mM}$ EDTA, $1 \%$ Triton X-100, $0.1 \%$ SDS, $0.1 \%$ deoxycholic acid) containing Complete mini EDTA-free protease inhibitor cocktail (Roche) and incubated for $5 \mathrm{~min}$ on ice. Human osteoclasts were differentiated for 12 days from CD14+ monocytes purified from human blood (Rigshospitalet Bloodbank, Copenhagen, Denmark) using Receptor Activator for Nuclear Factor $\kappa \mathrm{B}$ Ligand and Macrophage colony-stimulating factor as previously described [34]. Pellets were lysed in $500 \mu \mathrm{L}$ RIPA buffer. Ten to $20 \mu \mathrm{g}$ total protein of each lysate preparation was electrophoresed in polyacrylamide gels in denaturating condition (10\% dithiothreitol) with Full Range Rainbow protein marker (GE Healthcare, Buckinghamshire, UK). Proteins were blotted on nitrocellulose membranes (Whatman, Kent, UK), soaked in $10 \mathrm{mM} \mathrm{N}$-cyclohexyl-3-aminopropanesulfonic acid (Sigma) plus $10 \%$ ethanol pH 11, and incubated for 1 hour in blocking buffer (TBS $0.1 \%$ Tween-20 + 5\% skimmed milk powder). Nitrocellulose membranes were probed for 2 hours with primary antibodies at different dilutions in blocking buffer. After blocking, membranes were probed for 2 hours with anti-human CTR antibodies from different suppliers: SP1338P (Acris, Herford, Germany) diluted 1:200; H00000799-M01 (Abnova, Taipei City, Taiwan) diluted 1:200, 250618 (Abbiotec, San Diego, CA, USA) diluted $1: 200$ and Ab11042-50 (Abcam, Cambridge, MA, USA) diluted 1:2000. Subsequently, membranes were incubated for one hour at room temperature with secondary antibody, either rabbit anti-mouse 315035045 or goat anti-rabbit 111035003 (The Jackson Laboratory, Bar Harbor, ME, USA) diluted 1:10000. The Pierce ECL western blotting substrate (Thermo Fisher Scientific, Waltham, MA, USA) was used for detection and activated membranes were 
revealed with Amersham ECL HyperFilm (GE Healthcare) autoradiography films.

\section{Immunochemical localization of the human CTR}

Primary chondrocytes were isolated from cartilage as described above. The cells were fixed in $4 \%$ formalin (Lillie's fluid, Sigma-Aldrich, Glostrup, Denmark) for $10 \mathrm{~min}$ utes and rinsed in PBS. Endogenous peroxidases were blocked with $1 \%$ hydrogen peroxide in PBS for 20 minutes, followed by rinsing in TBS (Tris buffer saline). Next the cells were incubated with a rabbit polyclonal antibody raised against CTR (SP1338P, Acris antibodies, Herford, Germany), diluted 1:500 and incubated for 1 hour, including blocking agent (BSA, Sigma-Aldrich, Roedovre, Denmark). After rinsing in TBS, 5 drops of peroxidase-labeled EnVision+ anti-rabbit (Dako, Roedovre, Denmark) was added and incubated for 30 minutes. The cells were then rinsed and Dako DAB+ chromogen was add and the color reaction was stopped after 5 minutes, by rinsing in milli- $Q$ water. The cells were counterstained in Mayer's Hematoxylin for 1 minute, rinsed in tap water and ethanol. The stained cells were smeared on to a slide and covered with cover glass. Before isolation of the primary cells from cartilage, small pieces of the tissue were separated and fixed overnight in $4 \%$ formalin. The tissues were then embedded in paraffin and cut in 5 micrometer sections. They were then deparaffinated, endogenous peroxidase activity was blocked in $0.4 \% \mathrm{H}_{2} \mathrm{O}_{2}$ in $99 \%$ ethanol and samples were rehydrated and unmasked for 2 hours in citrate buffer, $\mathrm{pH}$ 6 at $60^{\circ} \mathrm{C}$. The sections were then incubated overnight at $4^{\circ} \mathrm{C}$ with polyclonal antibody diluted $1: 100$ in $1 \%$ casein blocking agent (Sigma-Aldrich, Roedovre, Denmark). Sections were then rinsed and peroxidase-labeled EnVision+ anti-rabbit (Dako, Roedovre, Denmark) was added and incubated for 30 minutes. The sections were then rinsed, Dako DAB+ chromogen was added and the color reaction was stopped after 10 minutes by rinsing in Milli-Q water. Finally, sections were counterstained in Mayer's Hematoxylin for 20 seconds, rinsed in tap water, dehydrated, mounted in Kaiser's glycerin jelly and covered. Both primary cells and cartilage sections were assessed under the microscope using CellA v2.7 software (Olympus, Ballerup, Denmark).

\section{Results}

Human chondrocytes express isoform 2 of the CTR

Chondrocytes isolated by enzymatic digestion were used to obtain high quality cartilage RNA for RT-PCR analysis, which was converted to cDNA. The nested PCR reaction (1:CALCR_F/CALCR_R; 2:CALCR_NF/ CALCR_NR) produced nanogram amounts of a single $1.5 \mathrm{kbp}$ amplicon. Purification and sequencing of this band confirmed the presence of the full coding sequence of the CALCR isoform 2 in the four patients included.
The sequences have been annotated and deposited at the INSDC nucleotide database (accession numbers FN994993 to FN994996). A number of signature polymorphisms were observed in sequencing electropherograms of those transcripts. Remarkably, FN994993 presented a heterozygous nonsense mutation at $\mathrm{nt}+473$, upstream of the start codon (Figure 1A). A traceable $n$ +1 secondary reading frame, denoting the presence of two distinct mRNA species, can be seen starting from the deleted $\mathrm{T}$ nucleotide. Three different $\mathrm{C}$-to- $\mathrm{T}$ single nucleotide polymorphisms (SNP) were also found at positions $-6,+1340,+1443$ (Figure 1B).

\section{Chondrocytes synthesize a $53 \mathrm{kDa}$ CTR protein consistent with isoform 2 of the CTR}

A panel of anti-CTR antibodies from different providers was tested in osteoclasts lysates to identify consensus immunoreactive band(s) attributable to the CTR. Four antibodies detected a $53 \mathrm{kDa}$ band consistent with the molecular weight of the osteoclast CTR (Figure 2A). Western blots of parallel samples of chondrocytes and osteoclasts lysates retrieved the same $53 \mathrm{kDa}$ band in both cell types. CTR levels in chondrocytes were lower for the same amount of total protein loaded (Figure 2B). Subsequent analysis of fresh chondrocyte preparations demonstrated the presence of sizeable amounts of CTR protein in those cells (Figure 2C).

\section{The CTR protein is localized the plasma membrane of primary chondrocytes}

The expression of the CTR was further investigated by immunohistochemistry. Immunoreactivity was observed in the plasma membrane of proliferative chondrocytes close to the articular surface (Figure $3 \mathrm{~A}, \mathrm{~B}$ and $3 \mathrm{C}$ ). The staining was seen as a dark brown ring following the cellular membrane. Similar staining was observed for primary chondrocytes, although the signal was also observed in the cytosol (Figure 3D). The cytosol staining was probably due the fact that the cell membrane has been permeabilized when isolated from the extracellular matrix by the detergents added. In many instances the cell surface was ruffled and due to the harsh handling of the tissue. Staining using isotype antibody control was negative (Figure 3E). Osteoclasts, isolated with magnetic beads (seen as round spots) and grown on bones slices, were used as positive controls (Figure 3F). Immunoreactivity was observed intracellularly in this multinuclei cell. The osteoclast was seated in a resorption pit; thus the surrounding bone becomes unfocused. No-antibody control was negative (data not shown).

\section{Discussion}

The results presented here are the strongest evidences published to date of the expression of calcitonin 


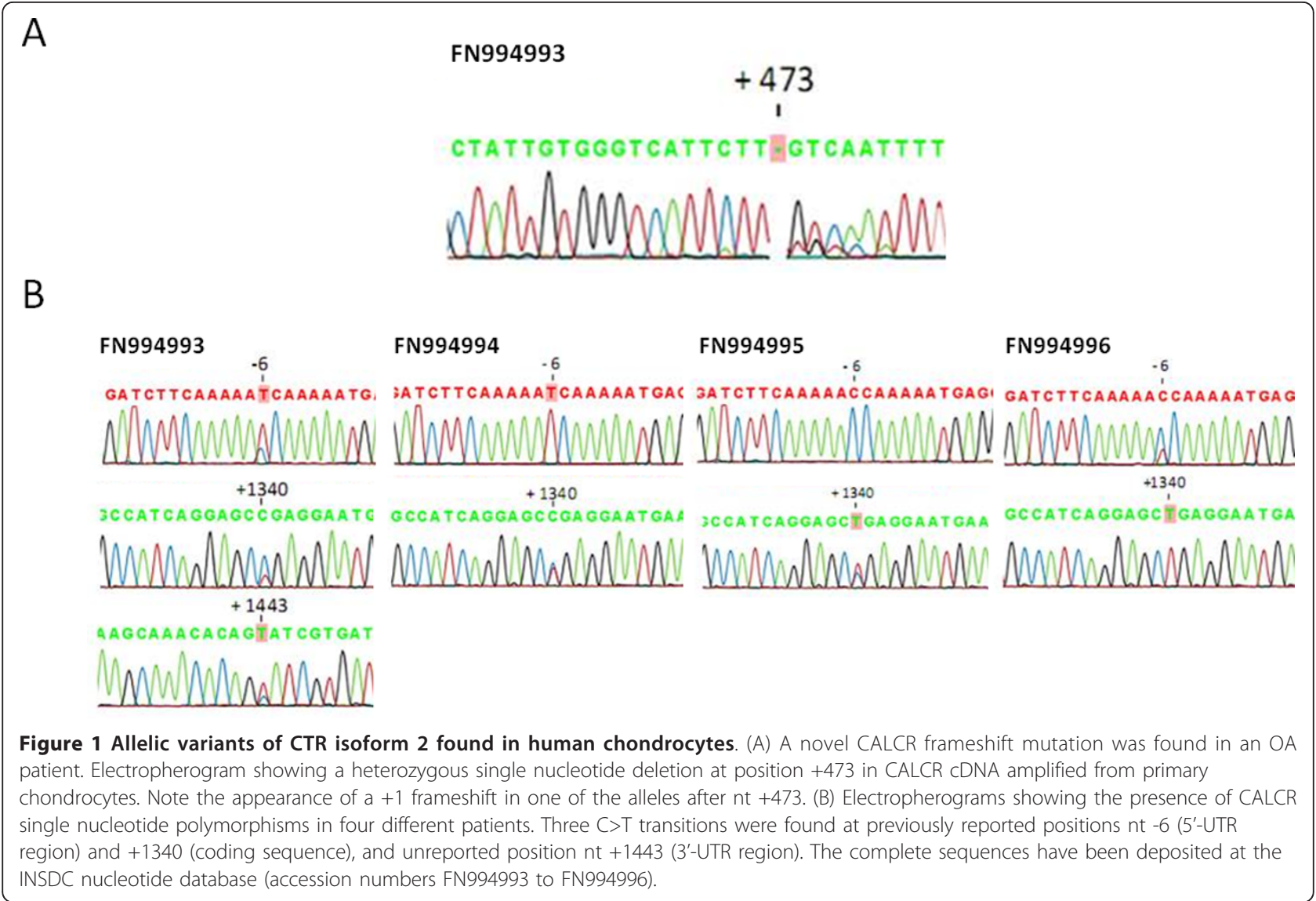

receptors in human articular cartilage. The nested PCR assay developed in this study led to the sequencing of the full coding sequence of CALCR gene transcripts of cartilage of OA patients. The CTR isoform 2 was consistently found in all four patients examined. By aligning experimental data to the NCBI Reference Sequence NM_001742.2, a number of genetic features became apparent. We confirmed the presence of two frequent polymorphisms at positions $-6 \mathrm{C}>\mathrm{T}$ and $+1340 \mathrm{C}>\mathrm{T}$. The former has been previously reported but not associated with any particular phenotype [35], while the later provokes a change in amino acid in the CTR protein, L447P that has been linked to bone mineral density (BMD) and osteoporosis (OP). In particular, heterozygosity at L447P has been linked to higher BMD at the femoral neck [36].

Interestingly, three patients in our study were heterozygous for L447P. Restriction fragment length polymorphism analysis of Japanese patients previouly identified this CALCR polymorphism as arising from a single nucleotide substitution leading to either a proline (CC phenotype), leucine (TT) or heterozygote (TC) genotype at amino acid position 447 [37]. Similar studies have been performed in different population such as postmenopausal Italian [38], Caucasian [39] and Polish [40] women, as well as in Caucasians, African-Americans, Asians and Hispanics [41] in order to assess the prevalence of those genotypes and investigate their potential association to BMD. While their authors extract different conclusions, these studies taken together suggest that the human CALCR gene plays a role in BMD and, ultimately, in the incidence of OP.

A novel polymorphism was found at $\mathrm{nt}+1443 \mathrm{C}>\mathrm{T}$ in the 3' untranslated region of the CALCR mRNA. The region contains regulatory sequences targeted by transcription factors, but the effect of such nucleotide change in the expression of the transcript is unknown. The most dramatic finding in the transcript sequences analyzed was a heterozygous missense mutation at position $n t+473$ caused by the deletion of a $\mathrm{T}$ base. This mutation provokes a frame shift in protein translation at amino acid residue 158 leading to early termination at residue 162, located in the first trans-membrane region of the receptor. It would be of interest to study the effect of such mutation and determine its cellular phenotype. Incidentally, a recent genetic association study concluded that a CA dinucleotide polymorphism in the calcitonin gene (CALCA) is associated with risk of 
A

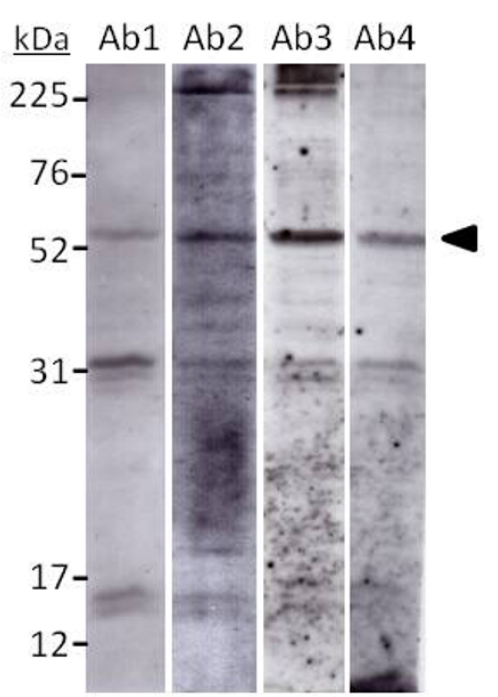

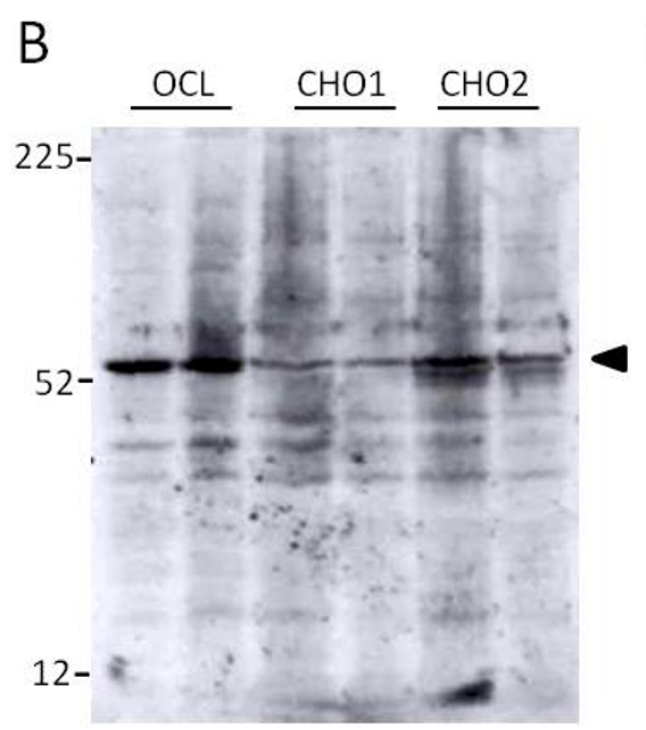

C

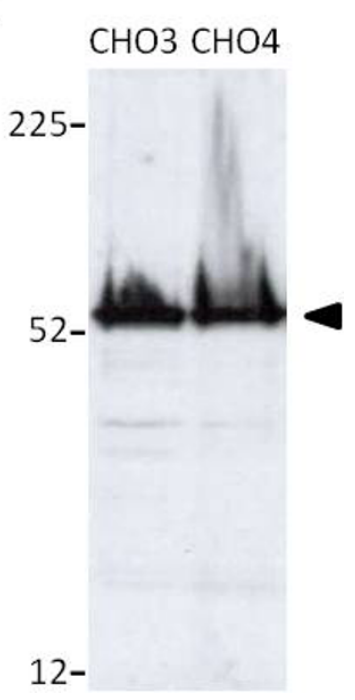

Figure 2 Western blot detection of CTR in human chondrocytes. (A) Screening of a panel of anti-CTR antibodies against human osteoclast lysates. A $53 \mathrm{kDa}$ band (arrow), consistent with the receptor's molecular weight, was chosen to evaluate antibody performance. Ab1: H00000799M01 diluted 1:200; Ab2: SP1338P dil. 1:200; Ab3: 250618 dil. 1:200; Ab4: Ab11042-50 dil. 1:2000. (B) Simultaneous detection of the 53 kDa CTR band in human osteoclasts and chondrocytes OCL: $10 \mu \mathrm{g}$ and $20 \mu \mathrm{g}$ protein of in vitro differentiated human osteoclasts lysates [34]; CHO1: 30 $\mu \mathrm{g}$ and $15 \mu \mathrm{g}$ protein of chondrocytes lysates from the same individual; $\mathrm{CHO}: 30 \mu \mathrm{g}$ and $15 \mu \mathrm{g}$ protein of chondrocytes lysates from a second individual. Antibody: Ab3, dil. 1:200. (C) Detection of CTR in $20 \mu \mathrm{g}$ protein cell lysates samples of freshly isolated chondrocyte from two different individuals. Antibody: Ab4, dil. 1:2000.

developing knee OA, reinforcing the idea that the CT system is deeply involved in cartilage health [42].

In an initial screening we found a common band of approximately $53 \mathrm{kDa}$ in osteoclasts lysates detected by different antibodies. This same band was also retrieved in chondrocytes. The theoretical molecular weight of the mature protein produced by isoform 2 , based on its amino acid sequence, is $55 \mathrm{kDa}$. Four putative $\mathrm{N}$-glycosylation sites, i.e. N28, N73, N125 and N130 are present in the amino terminal extracellular domain of the human CTR (UniProtKB/Swiss-Prot P30988). The western blot presented here, performed on freshly isolated chondrocyte pellets, showed a high molecular weight material smear above the $53 \mathrm{kDa}$ bands, but most of the immunoreactivity appears as a single discrete band (Figure $2 \mathrm{C}$ ). This would suggest that those glycosylation sites are not modified neither in human chondrocytes nor osteoclasts, in contrast to previous findings in heterologous expression studies of human CTR in monkey kidney COS-1 cells [43]. This same blot shows that chondrocytes are indeed capable of strong expression of CTR protein. Paradoxically, this strong expression was demonstrated using the same antibody used by Lin and coworkers [44]. The definitive confirmation of the expression of the CTR protein in human chondrocytes could be obtained by combined immunoprecipitation and mass spectrometry, but it was out of the scope of this study. These results were supported by the localization of the receptor to articular chondrocytes in cartilage sections from OA patients. Next it would be interesting to investigate to what degree different chondrocyte subpopulations express different amounts of CTR and whether the CTR is associated with other phenotype-specific proteins.

The results presented here allow us to conclude that human cartilage does express the calcitonin receptor. The main reason why other studies failed to find similar results may be the cell phenotype used in those investigations. The study published by Lin and coworkers was performed using cultured chondrocytes [45]. Other authors have provided evidences that culturing chondrocytes as an adherent monolayer invariably leads to a process of dedifferentiation whereby cells adopt a fibroblastic morphology, lose their chondrocyte-specific gene expression pattern and initiate or upregulate the expression of fibroblast-associated genes such as type I, III and $\mathrm{V}$ collagens and versican [46-48]. Therefore, chondrocytes dedifferentiated on plastic with fetal bovine serum is not recommendable as a representative system for cartilage cell biology studies, particularly in regards to gene expression profile.

\section{Conclusions}

As mentioned above, there are clear evidences of the beneficial effects of calcitonin in OA. However, its mode of action has not been yet fully clarified. OA is a 

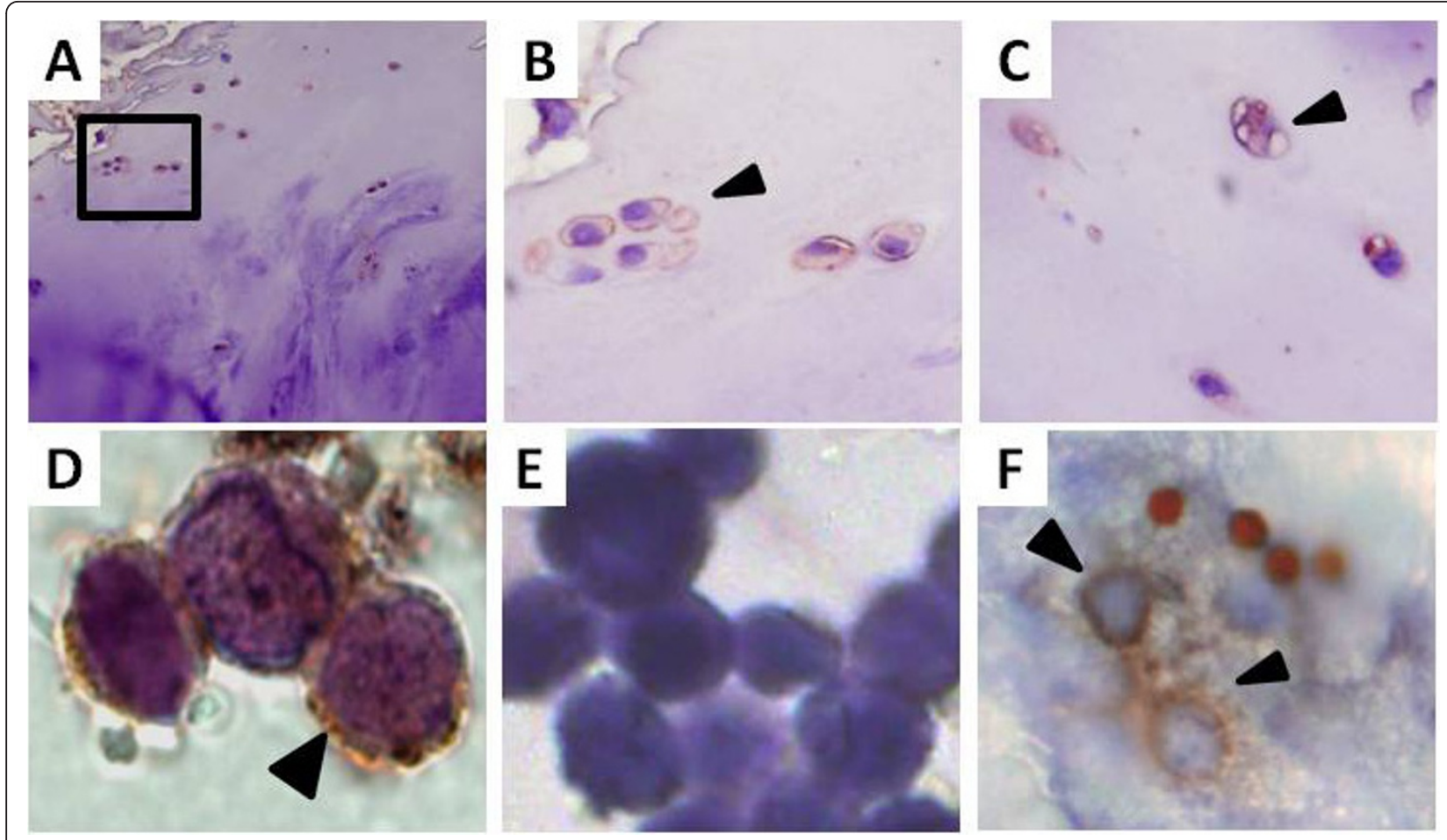

Figure 3 Immuno-localization of the CTR in human chondrocytes. (A) Human OA cartilage tissue, upper zone (obj. 20x). The square indicated the area of interest of the upper zone. (B) Clonal chondrocytes (clusters) positive for the CTR (obj. 40x). (C) Singular chondrocytes of the upper zone positive for the CTR (obj. 40X). (D) Overview picture of the deep zone with the tidemark marked in light pink (obj. 20X). (E) Close up of a column chondrocytes of the deep zone (obj. 100X). (F) Close up of a hypertrophic chondrocytes in the deep zone with positive staining in the fragmentized nucleus (obj. 100X). (G)-(I) Positive CTR staining in the cell membrane of primary chondrocytes of three different patients (obj. 100X). (J) Negative control: No staining is shown when omitting the primary antibody in the experimental protocol (obj. 100x). (K) Positive control: A differentiated osteoclast resorbing on bone shows the expected staining of the basolateral membrane where the receptor is expressed (obj. 100x). (L) Negative staining in synovial membrane (obj. 20x). Antibody staining: Acris sp1338p (red-brown) and positive staining is indicated with arrows. Cell nucleus was counter stained with Mayer's hematoxylin (blue).

complex disease that affects both bone and cartilage. Our results suggest that, beyond an indirect effect on cartilage via subchondral bone turnover [49], calcitonin may directly target chondrocytes in articular cartilage. Human cartilage cells do express the CTR. This will be confirmed in future clinical studies including a larger number of patients. The identification of isoform 2 in OA human cartilage allows for more targeted pharmacological investigations into the mode of action of calcitonin in OA treatment and prevention. Further research is also warranted into the intracellular mechanisms by which calcitonin protects chondrocytes, increases extracellular matrix synthesis and inhibits cartilage degradation.

\section{List of abbreviations used}

BMD: bone mineral density; CALCA: calcitonin-related polypeptide alpha gene; CALCR: calcitonin receptor gene; CAMP: cyclic adenosine 3'5'monophosphate; CDNA: complementary DNA; CT: calcitonin; CTR: calcitonin receptor protein; DMEM: Dulbecco's modified Eagle's medium; EB: elution buffer; EDTA: ethylenediaminetetraacetic acid; FCS: fetal calf serum; GPCR: G protein-coupled receptor; MMP: matrix metalloproteinase; OA: osteoarthritis;
OP: osteoporosis; PBS: phosphate buffered saline; PCR: polymerase chain reaction; PKC: protein kinase C; RIN: RNA integrity number; RIPA: radioimmunoprecipitation assay; RT-PCR: reverse transcription polymerase chain reaction; SCT: salmon calcitonin; SDS: sodium dodecyl sulfate; SNP: single nucleotide polymorphism; TBS: Tris buffer saline; UTR: untranslated region.

\section{Acknowledgements and funding}

We gratefully acknowledge the funding from the Danish Research Foundation (Den Danske Forskningsfond) supporting this work. Furthermore we would like to thank our technical staff, especially Inge Kolding.

\section{Author details}

'Nordic Bioscience A/S, Herlev Hovedgade 207, 2730 Herlev, Denmark. ${ }^{2}$ Gentofte University Hospital Orthopedic Surgery Unit, 2820 Gentofte, Denmark.

\section{Authors' contributions}

TSS directed the study and drafted the first version of the manuscript. MAK had the original idea for the manuscript and participated in discussing and drafting the manuscript. CB performed genetic and western blot experiments and participated in drafting the last version of the manuscript. $A C B J$ and BCS performed immunochemical analyses and drafted the final version of the manuscript. TC performed surgical procedures,

characterization of patients and participated in drafting the final version of the manuscript. All authors read and approved the last version of the manuscript. 


\section{Competing interests}

Morten Asser Karsdal owns stock in Nordic Bioscience. Anne C. Bay-Jensen and Bodil C. Sondergaard are full-time employees at Nordic Bioscience. Toni Segovia-Silvestre and Caroline Bonnefond were full-time employees at Nordic Bioscience at the time the work was performed, but are unaffiliated with Nordic Bioscience at the time of submission. Nordic Bioscience is involved in the development of oral salmon calcitonin for the treatment of OP and OA. Caroline Bonnefond and Tjorbjoern Christensen declare that they have no competing interests.

Received: 14 July 2011 Accepted: 13 October 2011

Published: 13 October 2011

\section{References}

1. Hellio MP, Peschard MJ, Cohen C, Richard M, Vignon E: Calcitonin inhibits phospholipase A2 and collagenase activity of human osteoarthritic chondrocytes. Osteoarthritis Cartilage 1997, 5(2):121-8.

2. Sondergaard BC, Wulf $H$, Henriksen $K$, Schaller S, Oestergaard S, Qvist P, et al: Calcitonin directly attenuates collagen type II degradation by inhibition of matrix metalloproteinase expression and activity in articular chondrocytes. Osteoarthritis Cartilage 2006, 14(8):759-68.

3. Karsdal MA, Sumer EU, Wulf H, Madsen SH, Christiansen C, Fosang AJ, et al: Induction of increased cAMP levels in articular chondrocytes blocks matrix metalloproteinase-mediated cartilage degradation, but not aggrecanase-mediated cartilage degradation. Arthritis Rheum 2007, 56:1549-58.

4. Suzuki F, Yoneda T, Shimomura Y: Calcitonin and parathyroid-hormone stimulation of acid mucopolysaccharide synthesis in cultured chondrocytes isolated from growth cartilage. FEBS Lett 1976, 70(1):155-8.

5. Kato Y, Nasu N, Takase T, Daikuhara Y, Suzuki F: A serum-free medium supplemented with multiplication-stimulating activity (MSA) supports both proliferation and differentiation of chondrocytes in primary culture. Exp Cell Res 1980, 125(1):167-74.

6. Burch WM: Calcitonin stimulates growth and maturation of embryonic chick pelvic cartilage in vitro. Endocrinology 1984, 114(4):1196-202.

7. Franchimont P, Bassleer C, Henrotin Y, Gysen P, Bassleer R: Effects of human and salmon calcitonin on human articular chondrocytes cultivated in clusters. J Clin Endocrinol Metab 1989, 69(2):259-66.

8. Khaldi L, Karachalios T, Galanos A, Lyritis GP: Morphometric changes in the epiphyseal plate of the growing and young adult male rat after longterm salmon calcitonin administration. Calcif Tissue Int 2005, 76(6):426-32.

9. Behets C, Williams JM, Chappard D, Devogelaer JP, Manicourt DH: Effects of calcitonin on subchondral trabecular bone changes and on osteoarthritic cartilage lesions after acute anterior cruciate ligament deficiency. J Bone Miner Res 2004, 19(11):1821-6.

10. El Haijaji H, Williams JM, Devogelaer JP, Lenz ME, Thonar EJ, Manicourt DH: Treatment with calcitonin prevents the net loss of collagen, hyaluronan and proteoglycan aggregates from cartilage in the early stages of canine experimental osteoarthritis. Osteoarthritis Cartilage 2004, 12(11):904-11.

11. Manicourt DH, Altman RD, Williams JM, Devogelaer JP, Druetz-Van Egeren A, Lenz ME, et al: Treatment with calcitonin suppresses the responses of bone, cartilage, and synovium in the early stages of canine experimental osteoarthritis and significantly reduces the severity of the cartilage lesions. Arthritis Rheum 1999, 42(6):1159-67.

12. Nielsen RH, Bay-Jensen AC, Byrjalsen I, Karsdal MA: Oral salmon calcitonin reduces cartilage and bone pathology in an osteoarthritis rat model with increased subchondral bone turnover. Osteoarthritis Cartilage 2011, 19(4):466-73.

13. Manicourt DH, Azria M, Mindeholm L, Thonar EJ, Devogelaer JP: Oral salmon calcitonin reduces Lequesne's algofunctional index scores and decreases urinary and serum levels of biomarkers of joint metabolism in knee osteoarthritis. Arthritis Rheum 2006, 54(10):3205-11.

14. Bagger $Y Z$, Tanko LB, Alexandersen $P$, Hansen HB, Qin $G$, Christiansen $C$. The long-term predictive value of bone mineral density measurements for fracture risk is independent of the site of measurement and the age at diagnosis: results from the Prospective Epidemiological Risk Factors study. Osteoporos Int 2006, 17(3):471-7.

15. Lin $H Y$, Harris TL, Flannery MS, Aruffo A, Kaji EH, Gorn A, et al: Expression cloning of an adenylate cyclase-coupled calcitonin receptor. Science 1991, 254(5034):1022-4.
16. Gorn AH, Lin HY, Yamin M, Auron PE, Flannery MR, Tapp DR, et al: Cloning, characterization, and expression of a human calcitonin receptor from an ovarian carcinoma cell line. J Clin Invest 1992, 90(5):1726-35.

17. Elshourbagy NA, Adamou JE, Swift AM, Disa J, Mao J, Ganguly S, et al: Molecular cloning and characterization of the porcine calcitonin generelated peptide receptor. Endocrinology 1998, 139(4):1678-83.

18. Nishikawa T, Ishikawa H, Yamamoto S, Koshihara Y: A novel calcitonin receptor gene in human osteoclasts from normal bone marrow. FEBS Lett 1999, 458(3):409-14.

19. Moore EE, Kuestner RE, Stroop SD, Grant FJ, Matthewes SL, Brady CL, et al: Functionally different isoforms of the human calcitonin receptor result from alternative splicing of the gene transcript. Mol Endocrinol 1995, 9(8):959-68.

20. Nakamura M, Hashimoto T, Nakajima T, Ichii S, Furuyama J, Ishihara Y, et al: A new type of human calcitonin receptor isoform generated by alternative splicing. Biochem Biophys Res Commun 1995, 209(2):744-51.

21. Perez Jurado LA, Li X, Francke U: The human calcitonin receptor gene (CALCR) at 7q21.3 is outside the deletion associated with the Williams syndrome. Cytogenet Cell Genet 1995, 70(3-4):246-9.

22. Gorn AH, Lin HY, Yamin M, Auron PE, Flannery MR, Tapp DR, et al: Cloning, characterization, and expression of a human calcitonin receptor from an ovarian carcinoma cell line. J Clin Invest 1992, 90(5):1726-35.

23. Kuestner RE, Elrod RD, Grant FJ, Hagen FS, Kuijper JL, Matthewes SL, et al: Cloning and characterization of an abundant subtype of the human calcitonin receptor. Mol Pharmacol 1994, 46(2):246-55.

24. Nussenzveig DR, Thaw CN, Gershengorn MC: Inhibition of inositol phosphate second messenger formation by intracellular loop one of a human calcitonin receptor. Expression and mutational analysis of synthetic receptor genes. J Biol Chem 1994, 269(45):28123-9.

25. Su Y, Chakraborty M, Nathanson MH, Baron R: Differential effects of the $3^{\prime}, 5^{\prime}$-cyclic adenosine monophosphate and protein kinase $C$ pathways on the response of isolated rat osteoclasts to calcitonin. Endocrinology 1992, 131(3):1497-502.

26. Albrandt K, Mull E, Brady EM, Herich J, Moore CX, Beaumont K: Molecular cloning of two receptors from rat brain with high affinity for salmon calcitonin. FEBS Lett 1993, 325(3):225-32.

27. Beaudreuil J, Balasubramanian S, Chenais J, Taboulet J, Frenkian M, Orcel P, et al: Molecular characterization of two novel isoforms of the human calcitonin receptor. Gene 2004, 343(1):143-51.

28. Wolfe LA III, Fling ME, Xue Z, Armour S, Kerner SA, Way J, et al: In vitro characterization of a human calcitonin receptor gene polymorphism. Mutat Res 2003, 522(1-2):93-105.

29. Nakamura M, Hashimoto T, Nakajima T, Ichii S, Furuyama J, Ishihara $Y$, et al: A new type of human calcitonin receptor isoform generated by alternative splicing. Biochem Biophys Res Commun 1995, 209(2):744-51.

30. Masi L, Becherini L, Gennari L, Colli E, Mansani R, Falchetti A, et al: Allelic variants of human calcitonin receptor: distribution and association with bone mass in postmenopausal Italian women. Biochem Biophys Res Commun 1998, 245(2):622-6.

31. Nicholson GC, Moseley JM, Sexton PM, Mendelsohn FA, Martin TJ: Abundant calcitonin receptors in isolated rat osteoclasts. Biochemical and autoradiographic characterization. J Clin Invest 1986, 78(2):355-60.

32. Sondergaard BC, Wulf $H$, Henriksen $K$, Schaller $S$, Oestergaard S, Qvist $P$, et al: Calcitonin directly attenuates collagen type II degradation by inhibition of matrix metalloproteinase expression and activity in articular chondrocytes. Osteoarthritis Cartilage 2006, 14(8):759-68.

33. Lin Z, Pavlos NJ, Cake MA, Wood DJ, Xu J, Zheng MH: Evidence that human cartilage and chondrocytes do not express calcitonin receptor. Osteoarthritis Cartilage 2008, 16(4):450-7.

34. Sorensen MG, Henriksen K, Schaller S, Henriksen DB, Nielsen FC, Dziegiel $\mathrm{MH}$, et al: Characterization of osteoclasts derived from CD14+ monocytes isolated from peripheral blood. J Bone Miner Metab 2007, 25(1):36-45.

35. Wolfe LA III, Fling ME, Xue Z, Armour S, Kerner SA, Way J, et al: In vitro characterization of a human calcitonin receptor gene polymorphism. Mutat Res 2003, 522(1-2):93-105.

36. Taboulet J, Frenkian M, Frendo JL, Feingold N, Jullienne A, de Vernejoul MC: Calcitonin receptor polymorphism is associated with a decreased fracture risk in post-menopausal women. Hum Mol Genet 1998, 7(13):2129-33 
37. Nakamura M, Morimoto $S$, Zhang Z, Utsunomiya H, Inagami T, Ogihara T, et al: Calcitonin receptor gene polymorphism in japanese women: correlation with body mass and bone mineral density. Calcif Tissue Int 2001, 68(4):211-5.

38. Masi L, Becherini L, Gennari L, Colli E, Mansani R, Falchetti A, et al: Allelic variants of human calcitonin receptor: distribution and association with bone mass in postmenopausal Italian women. Biochem Biophys Res Commun 1998, 245(2):622-6.

39. Taboulet J, Frenkian M, Frendo JL, Feingold N, Jullienne A, de Vernejoul MC: Calcitonin receptor polymorphism is associated with a decreased fracture risk in post-menopausal women. Hum Mol Genet 1998, 7(13):2129-33.

40. Drews K, Seremak-Mrozikiewicz A, Bartkowiak-Wieczorek J, Pienkowski W, Dubiel M, Mrozikiewicz PM: [Genetic polymorphism of the calcitonin receptor gene and bone mineral density in Polish population of postmenopausal women]. Ginekol Pol 2005, 76(8):612-8.

41. Wolfe LA III, Fling ME, Xue Z, Armour S, Kerner SA, Way J, et al: In vitro characterization of a human calcitonin receptor gene polymorphism. Mutat Res 2003, 522(1-2):93-105.

42. Magana JJ, Galvez-Rosas A, Gonzalez-Huerta C, Duarte-Salazar C, LaraAlvarado L, Soria-Bastida MA, et al: Association of the calcitonin gene (CA) polymorphism with osteoarthritis of the knee in a Mexican mestizo population. Knee 2010, 17(2):157-60.

43. Ho HH, Gilbert MT, Nussenzveig DR, Gershengorn MC: Glycosylation is important for binding to human calcitonin receptors. Biochemistry 1999, 38(6):1866-72.

44. Lin Z, Pavlos NJ, Cake MA, Wood DJ, Xu J, Zheng MH: Evidence that human cartilage and chondrocytes do not express calcitonin receptor. Osteoarthritis Cartilage 2008, 16(4):450-7.

45. Lin Z, Pavlos NJ, Cake MA, Wood DJ, Xu J, Zheng MH: Evidence that human cartilage and chondrocytes do not express calcitonin receptor. Osteoarthritis Cartilage 2008, 16(4):450-7.

46. Benya PD, Padilla SR, Nimni ME: Independent regulation of collagen types by chondrocytes during the loss of differentiated function in culture. Cell 1978, 15(4):1313-21.

47. Elima K, Vuorio E: Expression of mRNAs for collagens and other matrix components in dedifferentiating and redifferentiating human chondrocytes in culture. FEBS Lett 1989, 258(2):195-8.

48. Stokes DG, Liu G, Dharmavaram R, Hawkins D, Piera-Velazquez S, Jimenez SA: Regulation of type-II collagen gene expression during human chondrocyte de-differentiation and recovery of chondrocytespecific phenotype in culture involves Sry-type high-mobility-group box (SOX) transcription factors. Biochem J 2001, 360(Pt 2):461-70.

49. Karsdal MA, Leeming DJ, Dam EB, Henriksen $K$, Alexandersen $P$, Pastoureau $P$, et al: Should subchondral bone turnover be targeted when treating osteoarthritis? Osteoarthritis Cartilage 2008, 16(6):638-46.

doi:10.1186/1756-0500-4-407

Cite this article as: Segovia-Silvestre et al: Identification of the calcitonin receptor in osteoarthritic chondrocytes. BMC Research Notes 2011 4:407.

\section{Submit your next manuscript to BioMed Central and take full advantage of:}

- Convenient online submission

- Thorough peer review

- No space constraints or color figure charges

- Immediate publication on acceptance

- Inclusion in PubMed, CAS, Scopus and Google Scholar

- Research which is freely available for redistribution 